\title{
Transaortic, video-assisted removal of a mobile left ventricular apical thrombus in a patient with aortic stenosis and severe left ventricular dysfunction
}

\author{
Christina Williamson, MD, ${ }^{\mathrm{a}}$ Lori B. Sheehan, MD, ${ }^{\mathrm{b}}$ David M. Venesy, MD, ${ }^{\mathrm{c}}$ and \\ Richard S. D’Agostino, MD, ${ }^{\text {a }}$ Burlington, Mass
}

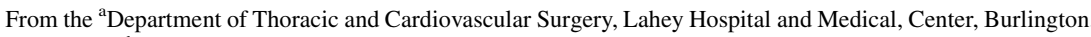
Mass; the ${ }^{\mathrm{b}}$ Department of Anesthesiology, Lahey Hospital and Medical, Center, Burlington, Mass; and the ${ }^{\mathrm{C}} \mathrm{De}-$ partment of Cardiology, Lahey Hospital and Medical Center, Burlington, Mass.

Disclosures: Authors have nothing to disclose with regard to commercial support.

Received for publication Aug 14, 2015; revisions received Sept 15, 2015; accepted for publication Sept 22, 2015; available ahead of print Oct 26, 2015.

Address for reprints: Christina Williamson, MD, Department of Thoracic and Cardiovascular Surgery, Lahey Hospital and Medical Center, 41 Mall Rd, Burlington, MA 01805 (E-mail: christina.williamson@lahey.org). J Thorac Cardiovasc Surg 2016;151:e1-3

$0022-5223 / \$ 36.00$

Copyright (C) 2016 by The American Association for Thoracic Surgery

http://dx.doi.org/10.1016/j.jtcvs.2015.09.091
}

Left ventricular thrombi are frequently encountered in patients with large anterior myocardial infarctions and significant anterior wall hypokinesis or akinesis. These clots occur in the acute or chronic phase of an infarction and are secondary to stagnant flow in the akinetic segment. ${ }^{1,2}$ They can occur in the settings of left ventricular aneurysm $^{3}$ and ischemic cardiomyopathy.

We encountered a patient with severe aortic stenosis, coronary artery disease, and severe left ventricular dysfunction. Intraoperative transesophageal echocardiography (TEE) demonstrated a protruding, mobile thrombus in the apex of the left ventricle that was not present on the patient's preoperative echocardiogram. Because this was a discrete, mobile, fresh thrombus, we felt it prudent to remove it to reduce the patient's risk of perioperative stroke.

\section{CLINICAL SUMMARY}

The patient was a 76-year-old woman with a recent nonST elevation myocardial infarction, progressive exertional dyspnea, and severe acute on chronic systolic and diastolic heart failure. Transthoracic echocardiography 2 months before surgery did not demonstrate a mobile thrombus in the left ventricle. It demonstrated severe diastolic dysfunction with severe global left ventricular dysfunction with an ejection fraction (EF) of $20 \%$. The patient had severe aortic stenosis, with calcified, immobile leaflets, a mean aortic valve gradient of $57 \mathrm{~mm} \mathrm{Hg}$, and a peak flow velocity across the valve of $5.3 \mathrm{~m} / \mathrm{s}$. Estimated pulmonary artery systolic pressure was $60 \mathrm{~mm} \mathrm{Hg}$, with normal right ventricular function. Coronary arteriography revealed a $70 \%$ proximal left anterior descending coronary artery stenosis.

Although the patient was at elevated risk with standard surgery, she did not meet the criteria for transcatheter aortic valve replacement. She therefore underwent aortic valve replacement and coronary artery bypass grafting. Intraoperative

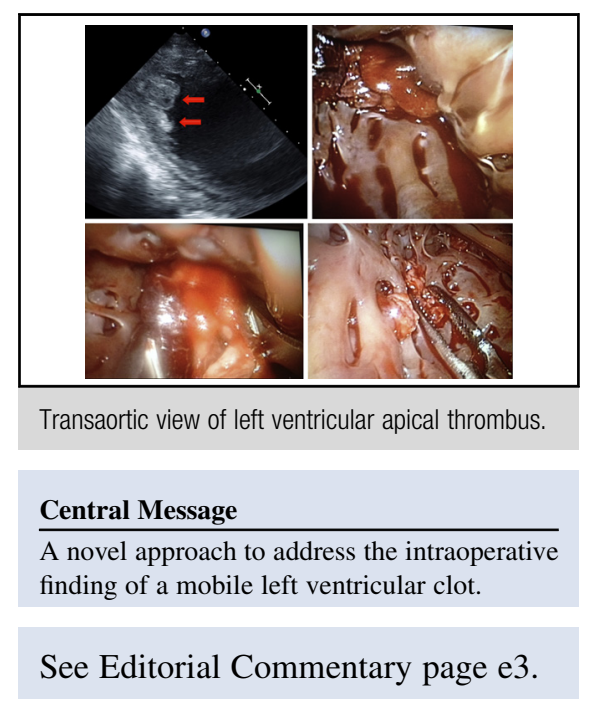

TEE revealed anteroseptal akinesis, an EF of $10 \%$ to $15 \%$, moderate to severe right ventricular dysfunction, and a large, mobile left ventricular apical thrombus (Figure 1). The patient was placed on cardiopulmonary bypass. Care was taken to avoid manipulating the left ventricle during cannulation to avoid mobilizing the apical thrombus. Retrograde cardioplegia was delivered for myocardial protection.

After removal of a heavily calcified aortic valve, a 5-mm deflectable tip Olympus ENDOEYE endoscope (Olympus America, Center Valley, Pa) was placed through the aortotomy into the left ventricle to visualize the thrombus (Figure 2). With a long, angled ring forceps, the bulk of the clot was removed (Figure 3). Residual thrombus was removed with Randall stone forceps (Figure 4). The left ventricular apex was irrigated copiously under direct vision to remove all residual thrombus and debris. The left anterior descending coronary artery was bypassed with a saphenous vein graft. The ostium of the right coronary artery was markedly narrowed by calcium, so the right coronary artery was bypassed with a saphenous vein graft as well. The valve was replaced with a size 23 Carpentier Edwards (Edwards Lifesciences Corp, Irvine, Calif) bovine pericardial valve, and the aorta was closed.

The first attempt at weaning the patient from cardiopulmonary bypass was unsuccessful so an intra-aortic balloon pump was placed. She was successfully weaned from cardiopulmonary bypass with an intra-aortic balloon pump and inotropic support. 


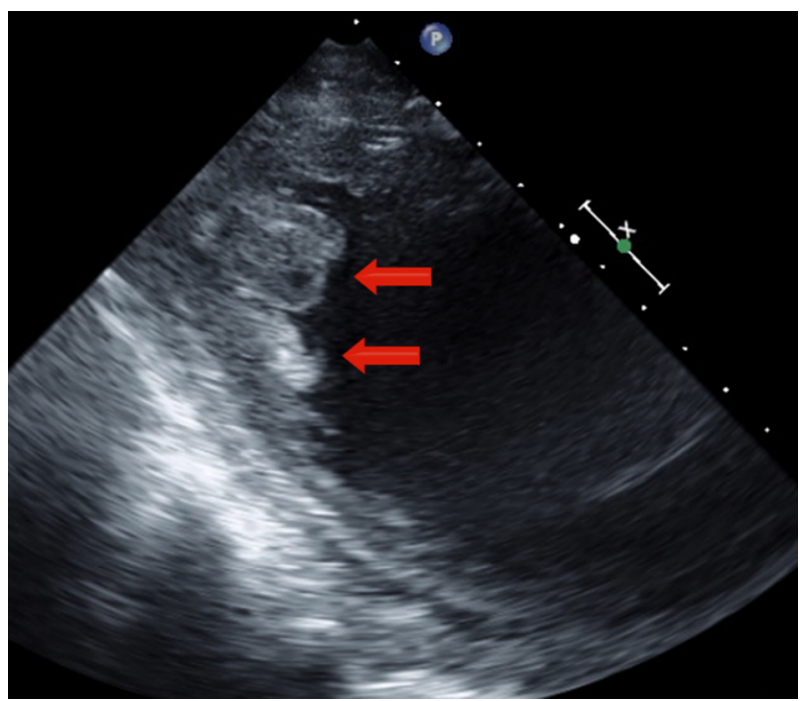

FIGURE 1. Transgastric 2-chamber transesophageal echocardiographic view, demonstrating a large, mobile thrombus (arrows).

A repeat intraoperative TEE revealed improved left ventricular function, with an EF of $25 \%$ to $30 \%$. There was no evidence of residual left ventricular thrombus, right ventricular function was improved, and the aortic valve prosthesis was functioning well. The patient's postoperative course was prolonged but uneventful, and she was discharged on postoperative day 13 without neurologic complications. Predischarge transthoracic echocardiography revealed improved left ventricular systolic function, with an $\mathrm{EF}$ of $40 \%$ to $45 \%$. The patient had anticoagulation with warfarin because she had a hypokinetic apical segment with stagnant flow, and it is our practice to administer anticoagulation to patients with left ventricular thrombus. At 3 years' follow-up, the patient is doing very well.

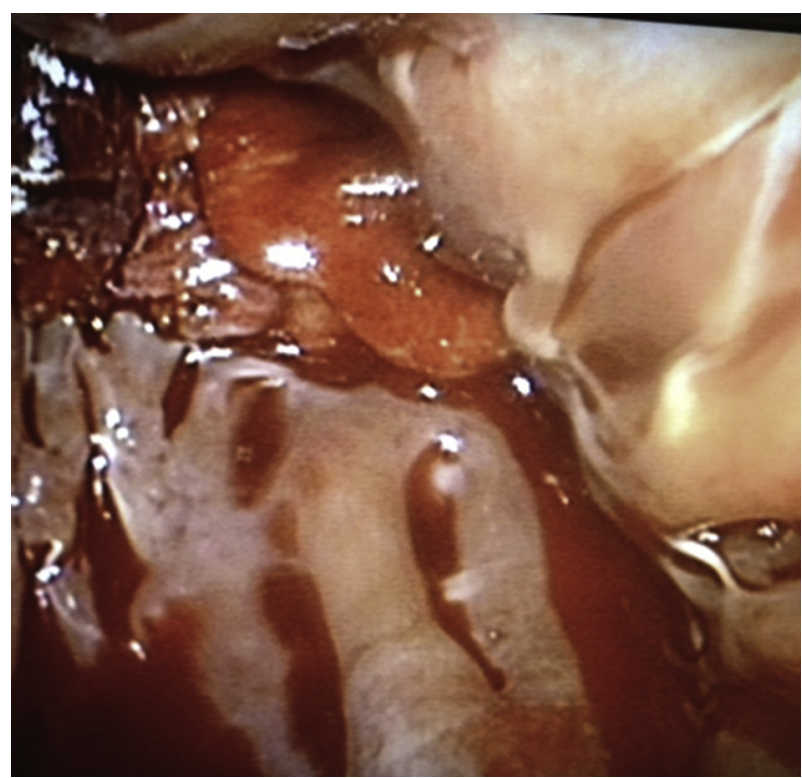

FIGURE 2. Transaortic view of the left ventricular apical thrombus with a 5-mm high-definition Olympus ENDOEYE endoscope.

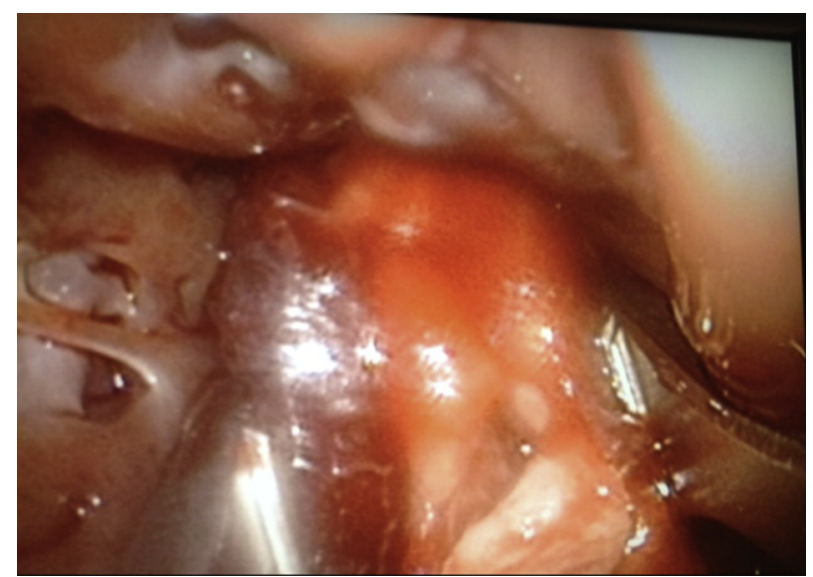

FIGURE 3. Extraction of the bulk of the apical thrombus with a long curved ring forceps.

\section{DISCUSSION}

It is important to recognize the presence of left ventricular thrombus in patients undergoing heart surgery. Intraoperative TEE can identify these thrombi, and one should minimize manipulation of the left ventricle. Most often, these are mural thrombi that are laminated along the wall of the ventricle and are not mobile. ${ }^{4}$ The majority are not surgically removed, because attempted extraction of embedded left ventricular mural thrombus is fraught with the risk of fragmentation and embolization. ${ }^{4}$ A mobile protruding thrombus, however, poses a particular risk for intraoperative or postoperative embolization. ${ }^{5,6}$ Removal of these thrombi during cardiac surgery has been described through left ventriculotomy, and this may be most appropriate for a left ventricular aneurysm that requires treatment. $^{7-9}$ Left ventriculotomy through an acute myocardial infarction, however, poses technical challenges in closing friable myocardium and may contribute to left ventricular dysfunction.

Tsukube first described transaortic video-assisted removal of a mobile left ventricular thrombus. ${ }^{10}$ A mediastinoscope

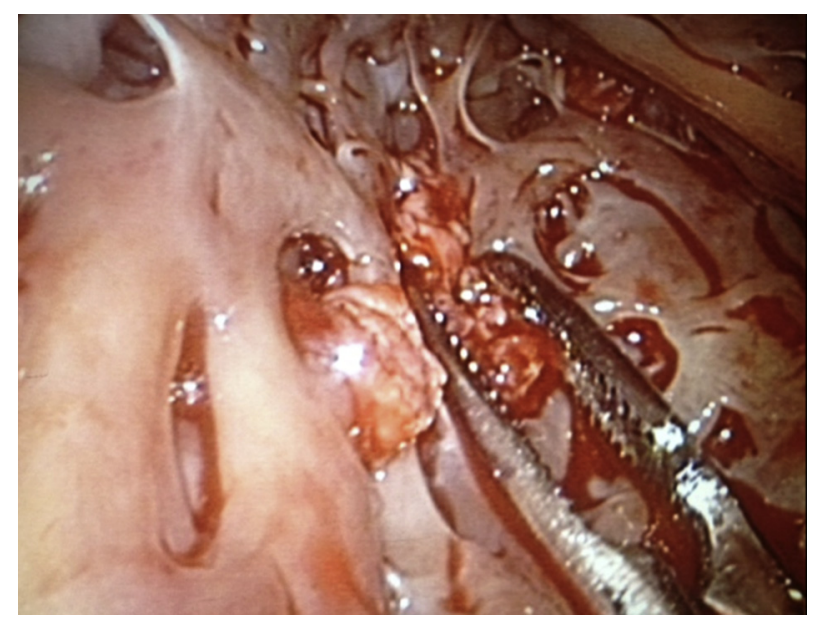

FIGURE 4. Extraction of the residual remnants of the thrombus with Randall stone forceps. 
has been passed across the mitral valve to extract a left ventricular thrombus. ${ }^{11}$ Video-assisted approaches have been described to remove left ventricular tumors from transaortic and transmitral approaches. ${ }^{12,13}$

The 5-mm scope can be placed across a normal aortic valve without traumatizing the leaflets as well. It is optimal to insert the scope over the top of the left coronary cusp, away from the septum, and to angle the flexible tip toward the apex. The advantage of the $5-\mathrm{mm}$ scope is that it allows adequate room for unencumbered use of other instruments to extract the thrombus, as well as a wider range of visibility inside the ventricle. Randall stone forceps, originally designed for common bile duct exploration, are ideally suited because they have varying degrees of curvature for reaching the apex of the ventricle.

We report a useful technique for removal of a mobile left ventricular thrombus with a transaortic video-assisted endoscopic approach. This technique provides an alternative to a left ventriculotomy when a protruding mobile left ventricular thrombus is found on intraoperative TEE.

\section{References}

1. Jordan RA, Miller RD, Edwards JE, Parker RL. Thrombo-embolism in acute and in healed myocardial infarction. I. Intracardiac mural thrombosis. Circulation. 1952;6:1-6.

2. Asinger RW, Mikell FI, Elsperger J, Hodges M. Incidence of left ventricular clot after acute transmural myocardial infarction. N Engl J Med. 1981;305:297-302.
3. Reeder GS, Lengyel M, Tajik AJ, Seward JB, Smith HC, Danielson GK. Mural thrombus in left ventricular aneurysm: incidence, role of angiography, and relation between anticoagulation and embolization. Mayo Clinic Proc. 1981;56: 77-81.

4. Spirito P, Bellotti P, Chiarella F, Domenicucci S, Sementa A, Vecchio C, et al Prognostic significance and natural history of left ventricular thrombi in patients with acute anterior myocardial infarction: a two dimensional echocardiographic study. Circulation. 1985;72:774-80.

5. Haugland JM, Asinger RW, Mikell FL, Elsperger J, Hodges M. Embolic potential of left ventricular thrombi detected by two-dimensional echocardiography. Circulation. 1984;70:588-98.

6. Hartman RB, Harrison EE, Pupello DF, Vijayanagar R, Sbar SS. Characteristics of left ventricular thrombus resulting in perioperative embolism. A complication of coronary artery bypass grafting. J Thorac Cardiovasc Surg. 1983;86:706-9.

7. Lew AS, Federman J, Harper RW, Anderson ST, Davis B, Stirling GR, et al. Operative removal of mobile pedunculated left ventricular thrombus detected by 2-dimensional echocardiography. Am J Cardiol. 1983;52:1148-9.

8. Sharma S, Ehsan A, Couper GS, Shernan SK, Wholey RM, Aranki SF. Unrecognized left ventricular thrombus during reoperative coronary artery bypass grafting. Ann Thorac Surg. 2004; 78:e79-80.

9. Nili M, Devin E, Jortner R, Strasberg B, Levy MJ. Surgical removal of a mobile, pedunculated, left ventricular thrombus: report of 4 cases. Ann Thorac Surg. 1988;46:396-400.

10. Tsukube T, Okada M, Ootaki Y, Tsuji Y, Yamashita C. Transaortic video-assisted removal a left ventricular thrombus. Ann Thorac Surg. 1999;68:1063-5.

11. Mazza IL, Jacobs JP, Aldousany A, Chang AC, Burke RP. Video-assisted cardioscopy for left ventricular thrombectomy in a child. Ann Thor Surg. 1998;66:248-50

12. Schroder C, Leukhardt WH, Hsiao MC, Farah MG, Markowitz AH. Transaortic video-assisted resection of a recurrent left ventricular myxoma. Ann Thorac Surg. 2013;95:340-2.

13. Agagi H, Irie H, Nakao Y, Sakai K. Transmitral resection of a left ventricular apical papillary fibroelastoma using video-assisted thoracoscopy. J Card Surg. 2013; 28:651-3.

\section{EDITORIAL COMMENTARY}

\section{Just try the experiment}

\author{
John R. Doty, MD

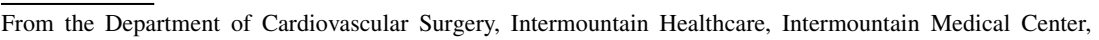 \\ Murray, Utah. \\ Disclosures: Author has nothing to disclose with regard to commercial support. \\ Received for publication Oct 7, 2015; accepted for publication Oct 8, 2015. \\ Address for reprints: John R. Doty, MD, Department of Cardiovascular Surgery, Intermountain Healthcare, Inter- \\ mountain Medical Center, 5169 S. Cottonwood Street, Murray, UT 84107 (E-mail: john.doty@imail.org). \\ J Thorac Cardiovasc Surg 2016;151:e3-4 \\ $0022-5223 / \$ 36.00$ \\ Copyright (c) 2016 by The American Association for Thoracic Surgery \\ http://dx.doi.org/10.1016/j.jtcvs.2015.10.029
}

The article in this issue of the Journal by Williamson and colleagues $^{1}$ from the Lahey Hospital represents an intriguing and clever solution to what is becoming an increasingly common scenario in modern cardiothoracic surgery - the older patient with mixed, advanced cardiovascular disease. Williamson and colleagues sought out a method that could effectively address the concomitant problems of valvular disease, atherosclerosis, and severe heart

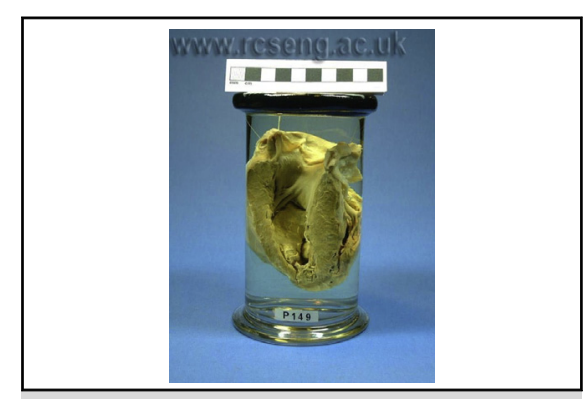

Preserved cardiac specimen demonstrating thrombus layering inside the left ventricle.

Central Message

Consider and explore multiple treatment options for complex, advanced cardiovascular disease.

See Article page e1. 